\title{
LIAISON INTERPRETING OU ESCORT INTERPRETING? UM ESTUDO SOBRE A INTERPRETAÇÃO DE LIBRAS-PORTUGUÊS NA ÁREA EMPRESARIAL
}

\author{
LIAISON INTERPRETING OR ESCORT INTERPRETING? \\ A STUDY ONLIBRAS-PORTUGUESE INTERPRETATION \\ WITHIN THE BUSINESS AREA
}

\begin{abstract}
LIAISON INTERPRETING O ESCORT INTERPRETING?
UN ESTUDIO SOBRE LA INTERPRETACIÓN DE LA LENGUA B RASILEÑA DE SEÑAS-PORTUGUÉS EN EL ÁREA EMPRESARIAL
\end{abstract}

\author{
Aline Vanessa Poltronieri-Gessner * \\ Silvana Aguiar dos Santos ${ }^{* *}$
}

\section{Resumo}

No Brasil, os conceitos de "interpretação de ligação" e de "interpretação de acompanhamento", usados nas línguas de sinais, têm sido pouco abordados na produção acadêmica dos Estudos da Interpretação. Este texto apresenta e discute algumas nomenclaturas designadas para a atuação de intérpretes na esfera empresarial tal como a interpretação de acompanhamento, também conhecida como escort interpreting ou liaison interpreting, e popularmente disseminada como "interpretação de ligação", ou como aparece nas produções acadêmicas, "interpretação comunitária". Respaldam teoricamente este trabalho: Couto et al. (2010), Torres e Silva (2014), Hsieh (2003), Pöchhacker (2010) e Russo (2004). Na Introdução, este trabalho apresenta as principais demandas desse campo; na primeira seção, propõe-se a uma reflexão sobre os Estudos da Interpretação e a esfera empresarial; nas seções seguintes, discute a variedade de nomenclaturas atribuídas ao profissional que trabalha neste campo e as implicações desses conceitos para a atuação dos intérpretes de Libras-Português, para enfim, nas considerações finais, retomar os principais tópicos discutidos no texto a partir de uma perspectiva mais completa e madura.

Palavras-chave: Estudos da Interpretação. Interpretação de acompanhamento. Interpretação de ligação. Intérpretes de Libras-Português. Área empresarial.

\section{Introdução}

\footnotetext{
* Tradutora-Intérprete de Libras-Português da Universidade Federal de Santa Catarina. Bacharel em Letras Libras - Língua Brasileira de Sinais pela UFSC. Email: aline.poltronieri@ hotmail.com

** Professora do Departamento de Língua de Sinais Brasileira (LSB/UFSC) e do Programa de Pós-Graduação em Estudos da Tradução (PGET/UFSC). Colaboradora do Programa de Pós-Graduação em Estudos da Tradução (POET/UFC). Email: s.santos@ufsc.br
} 
O processo de globalização tem contribuído para a expansão de diversos contextos sociais, econômicos, linguísticos, culturais, dentre outros. Nos setores da indústria e do comércio, por exemplo, nota-se um aumento considerável nas exigências por custos reduzidos e, ao mesmo tempo, por um aumento da diversidade, fabricação e venda de itens que atendam às demandas de uma sociedade contemporânea. Neste cenário, hoje, cabe às indústrias o desafio de transformar insumos em produtos que contribuirão para prover os diferentes tipos de necessidade da nossa sociedade.

Seja no mercado nacional, seja no mercado internacional, as indústrias e comércios trazem inúmeros benefícios, além, é claro, de fazer a economia girar. As empresas têm o poder de ampliar a projeção e a visibilidade da região em que se encontram estabelecidas; expandir o mercado de trabalho, com a geração de vagas de emprego; absorver a mão de obra local e, por vezes, incentivar programas de formação continuada para os funcionários. A atuação das empresas impacta a produção de mercadorias que movimentam a economia e cooperam para a dinâmica da logística empresarial. Nesse contexto, as organizações podem ser classificadas, de acordo com o número de funcionários e outras variáveis, em micro, pequena, média e grande porte. As empresas com mais de 100 funcionários, segundo a Lei nº 8.213/1991, são obrigadas a reservar uma porcentagem de suas vagas para reabilitados da Previdência Social ou Pessoas com Deficiência (PCDs).

A inclusão desses profissionais, inclusive de pessoas surdas ou com deficiência auditiva no mercado de trabalho, é um dos temas habitualmente explorados pela mídia. Um exemplo disso é a reportagem intitulada "Mercado inclusivo: lei de inclusão não apenas disciplina empresas, mas estimula portadores de deficiência a buscar qualificação", veiculada pelo Jornal de Santa Catarina. O texto jornalístico ${ }^{1}$ mostra a foto de um trabalhador "deficiente auditivo" em seu local de trabalho. A reportagem conta parte da história de vida do funcionário e menciona a legislação, que prevê a inclusão de PCDs nas empresas e assinala as adaptações necessárias para receber esses funcionários. O texto evidencia que as alterações devem partir das entidades empregadoras observando as demandas de seu empregado, sejam elas arquitetônicas, como o espaço físico, ou ainda, linguísticas. A matéria veiculada naquele jornal comenta a importância do papel e da presença do Intérprete de Libras, embora não apresente detalhes sobre o serviço de tradução ou interpretação.

Até então, pouco se sabia sobre os serviços de interpretação no par linguístico 
Libras-Português, ou ainda, sobre os profissionais que atuam na esfera empresarial. Alguns motivos cooperam para a invisibilidade dos serviços de interpretação nesse meio: há uma escassez de materiais ou produções acadêmicas sobre esta temática, de modo que são raras as discussões sobre a relevância desse profissional na esfera empresarial. Neste artigo, o nosso foco é apresentar e discutir algumas nomenclaturas atribuídas ao profissional que trabalha nesse campo, abordando algumas implicações desses conceitos, a fim de facilitar o entendimento sobre a atuação de intérpretes de Libras-Português na esfera empresarial.

\section{Reflexões sobre os Estudos da Interpretação e a esfera empresarial}

No Brasil, de acordo com Santos (2013) e Pereira (2010), a maioria das pesquisas sobre tradução e interpretação de línguas de sinais aponta o contexto educacional como o mais investigado, especialmente, nas teses e dissertações. Ou seja, os registros sobre interpretação de Libras-Português na esfera empresarial são praticamente inexistentes nas produções acadêmicas investigadas pelas autoras.

A fim de compreender melhor essa esfera de atuação, empregou-se a pesquisa ${ }^{2}$ bibliográfica e o exame das seguintes expressões: interpretação de acompanhamento, interpretação de ligação, interpretação liaison,escort interpreting e interpretação empresarial. Pode-se verificar que essa esfera de interpretação apresenta uma série de variações no uso da sua nomenclatura, impactando na atuação dos profissionais. Em algumas produções acadêmicas, a interpretação liaison, também conhecida como interpretação de diálogo, assemelha-se à interpretação comunitária. Um exemplo disso foi trazido por Pöchhacker (2004) ${ }^{3}$, pois o autor distingue duas esferas de interpretação: conferência e diálogo/ligação.

São inúmeros os espaços de atuação para intérpretes. Eles podem trabalhar em contextos educacionais, jurídicos, saúde e tantos outros que, de algum modo, se relacionem com as duas esferas. Cada um desses contextos apresenta determinadas características e singularidades que se assemelham em alguns aspectos e se diferem em outros, isso contribuiu para que Pöchhacker (2004) criasse um espectro conceitual da interpretação. Por exemplo, características como caráter internacional, papéis profissionais, discurso monológico utilizado, frequentemente, em palestras, congressos e eventos, relações de poder entre os participantes da interpretação que se igualam ou são próximas, são alguns dos elementos que caracterizam a interpretação de 
conferência. Quando se recorre aos paradigmas que caracterizam a história dos Estudos da Interpretação, segundo Pöchhacker (2010), é possível constatar que a interpretação de conferência foi objeto central de investigação na produção acadêmica analisada, tomando como base quatro paradigmas: Teoria Interpretativa, Processo Cognitivo, Processo Neurolinguístico e Orientação ao Texto Alvo.

$\mathrm{Na}$ interpretação liaison (diálogo) destaca-se o caráter intrassocial (comunitário) no qual a comunicação se efetiva, na maioria das vezes, com o diálogo face a face, permitindo que ambos participantes possam se expressar no transcorrer da interação. Pöchhacker (2010) alerta sobre o diferencial de poder existente nas interações comunicativas nos diferentes contextos de interpretação. Nos contextos de interpretação comunitária, o diferencial de poder entre os indivíduos que recebem os serviços de interpretação é bastante discrepante. Por outro lado, nos contextos de conferência, o diferencial de poder que existe entre os indivíduos é bem mais próximo.

Esse diferencial de poder pode ser observado em atitudes, comportamentos, assimetrias de poder que ocorrem nas interações entre os participantes do ato interpretativo, em diversas situações de atendimentos. Podem ser marcados por esse diferencial de poder contextos médico ou de saúde (consultas, cirurgias, internações), jurídico e policial (delegacias, audiências e julgamentos), educacional (instituições de ensino), empresarial (entrevistas, reuniões e treinamentos), dentre outros contextos referentes a interesses sociais e comunitários. Ainda que a interpretação comunitária seja exercida há muito tempo, em termos de pesquisa ela emerge no final da década de oitenta.

Os elementos da interação e do discurso, apontados por Cecília Wadensjö (2002) e corroborados por Pöchhacker (2010), trazem um novo olhar para a relação triádica $^{4}$ da interpretação, tratada pela maioria das pesquisas anteriores com foco no processamento mental-cognitivo. Identificar e compreender as fases, as etapas e os desafios enfrentados pelos intérpretes, do ponto de vista do processamento, era bastante comum nas produções acadêmicas por volta dos anos 60 e 70 .

Apesar de Pöchhacker (2010) apresentar a semelhança das características que envolvem a interpretação liaison e a interpretação comunitária, alguns elementos merecem ser problematizados. Um desses refere-se ao espaço público e privado. Nas produções acadêmicas da área dos Estudos da Interpretação - seja em teses ou dissertações, seja em artigos seminais - a interpretação comunitária, frequentemente, é 
definida como aquela que busca garantir o acesso dos cidadãos, que não conhecem a língua de um determinado país, aos diferentes serviços públicos. A interpretação de liaison, termo que pode ser traduzido por ligação, articulação, e compreendida, nesse contexto, como “diálogo”, não se aplica somente ao setor público. Queiroz (2011, p.37) afirma que:

Interpretação comunitária, social, cultural, de ligação ou, ainda, de serviço público são alguns dos termos usados para alcunhar a atividade dos intérpretes que atuam em interações de diálogos intrassociais, especialmente os que ocorrem em encontros em que os participantes negociam direitos e deveres.

Às vezes, a distinção entre os conceitos de interpretação liaison (diálogo) ou escort interpreting (interpretação de acompanhamento) não é facilmente identificada nas produções da área dos Estudos da Interpretação em nosso país. É comum ver a menção da interpretação liaison (diálogo) ou do termo escort interpreting/ (interpretação de acompanhamento) próxima do campo da interpretação comunitária. Por isso, a seguir, propõe-se a reflexão de alguns desses conceitos e das suas implicações.

\section{Liaison interpreting ou escort interpreting? O uso dos diferentes conceitos e implicações}

Os Estudos da Interpretação como uma subárea de pesquisa emergiram nas últimas décadas. Sobre a obra Introducing Interpreting Studies, de Franz Pöchhacker (2004), Queiroz observa que o autor "faz uma revisão sobre tradições de enfoques de pesquisa ou paradigmas ${ }^{5}$, que emergiram do campo dos estudos da interpretação desde os anos setenta, quando a interpretação se estabeleceu como um campo de pesquisa acadêmica" (2011, p.34).

No Brasil, as tendências de pesquisas sobre interpretação, sejam línguas orais, sejam línguas de sinais estão em fase de consolidação. Rodrigues e Beer (2015) realizaram importantes contribuições no que concerne à emergência dos Estudos da Tradução e da Interpretação de Línguas de Sinais (ETILS). Os autores demonstram como os ETILS afiliam-se aos Estudos da Tradução ou Estudos da Interpretação. Para isso, Rodrigues e Beer (2015) analisaram obras seminais, a saber: The Translation Studies Reader, organizado por Lawrence Venuti; The Interpreting Studies Reader, organizado por Franz Pöchhacker e Miriam Shlesinger; Routledge Encyclopedia of 
Translation Studies, organizado por Mona Baker e Gabriela Saldanha e, por fim, The Routledge Companion to Translation Studies, organizado por Jeremy Munday.

No que tange à interpretação de línguas orais, Cavallo e Reuillard (2016) investigaram as tendências de pesquisa no Brasil. Ou seja, as autoras mostram como os Estudos da Interpretação estão delineando sua trajetória em nosso país, focando, justamente, nas tendências atuais da pesquisa brasileira. As reflexões de Cavallo e Reuillard (2016) estão voltadas somente para as línguas orais e apontam a escassez de pesquisas sobre interpretação na pós-graduação. As autoras apresentam uma série de razões que explicam o número diminuto das pesquisas.

[...] primeiramente, o fato de a Interpretação ser uma área que começou a ser estudada e que passou a se fazer presente nas universidades do mundo inteiro somente a partir da metade do século passado (e no Brasil, a partir dos anos noventa), ao contrário das muitas décadas de estudo sobre a tradução escrita. Em segundo lugar, é inegável que a interpretação é profissionalmente menos praticada do que a tradução escrita, dado que os eventos em que é necessária uma intermediação linguística oral entre duas partes que não entendem a mesma língua/cultura são numericamente inferiores em relação às demandas de tradução escrita. Em terceiro lugar, a escassa presença de cursos de formação de intérpretes no Brasil limita bastante a pesquisa na pós-graduação, os Estudos da Interpretação estando presentes ainda em poucas universidades brasileiras (CAVALLO E REUILLARD, 2016, p.365).

Diante do exposto, observa-se que as pesquisas sobre interpretação de línguas de sinais e de línguas orais têm aumentado consideravelmente em nosso país. Porém, pesquisas que tratam das especificidades da interpretação, tais como interpretação de conferência, interpretação de diálogo, interpretação comunitária, interpretação de serviços públicos, interpretação de acompanhamento, dentre outras, são bastante raras. Dito de outro modo, Pereira (2010), Santos (2013), Rodrigues e Beer (2015), Cavallo e Reuillard (2016) registraram nos resultados poucos indícios sobre distintos tipos de interpretação.

Embora os resultados das pesquisas revelem muito pouco sobre os diferentes tipos de interpretação, isto não quer dizer que, na prática profissional, tais contextos não existam. No âmbito internacional, nos mapeamentos apresentados pela área dos Estudos da Tradução, especificamente naquele proposto pela editora St. Jerome, temos diferentes tipos de interpretação e o próprio campo dos Estudos da Interpretação configura-se como subárea dos Estudos da Tradução. Ou seja, nesse mapeamento, a 
editora apresenta um campo denominado "Interpretação para a comunidade/Serviço Público/Interpretação de Diálogo". Diante dessa realidade, este artigo problematiza os conceitos de liaison interpreting e escort interpreting, traduzidos, respectivamente, como interpretação de diálogo e interpretação de acompanhamento.

A área empresarial é um campo de atuação para intérpretes de diferentes pares linguísticos. Esses profissionais realizam as interpretações de línguas orais ou de sinais nas mais diversas situações corporativas: seja em cenas de negociação entre as partes, seja em acompanhamento de pequenos grupos às reuniões específicas. Mas, será que o conceito de interpretação liaison seria o único termo adotado nesse meio? Quais são as características desse tipo de interpretação para alguns autores?

Nesta seção, reunimos os resultados da pesquisa bibliográfica, que revelou uma diversidade na nomenclatura para a interpretação em contextos empresariais. Alguns dos termos mais comuns são interpretação de acompanhamento, usado por Couto et al. (2010), Torres e Silva (2014) ${ }^{6}$ e Scapol (2016), e liaison interpreting, usado por Pöchhacker (2010), Hsieh (2003) e Russo (2004). Algumas variações desses conceitos podem ser encontradas na literatura em geral, tais como: interpretação de enlace, interpretação em trâmite, interpretação de negócios ou interpretação em contexto empresarial.

No cenário nacional, o tema é ainda incipiente, assim como a circulação da produção acadêmica voltada para esse contexto. Em alguns textos, como nos escritos de autoria de Rodrigues (2010), Pereira (2008, 2015), Torres e Silva (2014) e Scapol (2016), temos registros que mencionam a existência de estudos ou, ainda, do serviço de interpretação para contextos de trâmite ou acompanhamento.

Um dos motivos que pode explicar a fraca visibilidade e a rara produção acadêmica sobre interpretação liaison e escort interpreting é a falta de materiais traduzidos, já que a maioria dos títulos sobre o tema foi publicada em diversas línguas estrangeiras. Em alguns casos, obras que foram publicadas apenas uma vez ou que já estão esgotadas dificultam a circulação do tema. Um exemplo disso é o livro intitulado "Liaison Interpreting: A Handbook", de Adolfo Gentile, Uldis Ozolins e Mary Vasilakakos, que está esgotado, o que torna o acesso à obra difícil e restrito.

No contexto internacional, o levantamento bibliográfico realizado para este trabalho revela certa quantidade de produções acadêmicas sobre os conceitos de liaison interpreting e de escort interpreting. No entanto, alguns dos materiais encontrados 
destacam os aspectos terminológicos e a elaboração de glossários das línguas envolvidas no ato interpretativo como, por exemplo, Ginezi (2008) que ilustra um caso do setor cafeeiro. Tais instrumentos contribuem significativamente para a atuação do profissional, auxiliando os intérpretes na preparação de materiais prévios ou mesmo ampliando o vocabulário técnico exigido para uma determinada interpretação. Outra parte dos materiais registrados na pesquisa sobre interpretação liaison ou diálogo contempla a atuação propriamente dita do intérprete e a relação deste profissional com os participantes da esfera empresarial.

Para alguns autores como Couto et al. (2010), a liaison interpreting pode aproximar-se da interpretação comunitária ou de comunidade, já que partilha algumas características referentes ao contexto dialógico, mesmo mantendo determinadas especificidades. Os autores destacam a distinção entre a interpretação liaison e a interpretação comunitária.

Enquanto a "Interpretação de Liaison" remete para um acompanhamento em contexto de negócios ou de visita cultural ou turística, a "Interpretação de Comunidade" reporta-se à mediação linguística de alguém que não fala a linguagem da maioria, normalmente no âmbito judicial, social, ou de saúde. (COUTO et al., 2010, p.48-49).

Conforme a distinção feita pelos autores, as características que separam interpretação de liaison e de comunidade são bastante sutis, possibilitando, em alguns casos, que esses tipos de interpretação sejam tidos como sinônimo ou mesmo confundidos. Partindo dessas considerações, a produção acadêmica que discute esse tema menciona questões sobre a formação necessária dos intérpretes que atuam nesse meio empresarial ou de negócios. No contexto italiano, Russo (2004, p.3) observa que:

[...] "intérprete ditrattativa" é um pós-graduado treinado e corresponde a um "intérprete de ligação" (conforme definido por Gentile et al., 1996) ou a um "intérprete de enlace" (conforme definido por Collados Aís e Fernández Sánchez 2001), o qual não pertence necessariamente ao mesmo grupo étnico do cliente e atua também em contextos de negócios ${ }^{7}$.

Segundo Russo (2004), no que concerne ao grupo étnico, a interpretação liaison não faz exigências para que os intérpretes pertençam ao mesmo grupo étnico do cliente, pois parte-se da premissa de que, confirmado o domínio linguístico, cultural e a 
formação requisitada, o profissional estará apto a atender a demanda do contratante. Nesta perspectiva, o cenário italiano revela a importância da formação para o intérprete e deixa claro que, independentemente das demandas, o profissional que irá atuar precisa realizar treinamento para ser declarado apto ao trabalho e realizá-lo de forma satisfatória.

Por outro lado, a produção acadêmica da área registra o termo Escort interpreting, também conhecido como interpretação de acompanhamento para contextos empresariais. Esse tipo de interpretação caracteriza-se por acompanhar o cliente ou um grupo de participantes aos respectivos lugares que necessitam do serviço de interpretação, ou seja, em visitas de representantes governamentais, empresários ou líderes políticos. Os espaços de atuação na interpretação de acompanhamento também incluem a condução do cliente ao translado (aeroporto, hotel, local de trabalho), além de passeios e outros eventos sociais, segundo Torres e Silva (2014).

Cabe salientar que Couto et al. (2010), a partir das pesquisas realizadas na cidade de Porto, em Portugal, intitula a interpretação de acompanhamento "para descrever uma situação comunicativa que decorre em contextos variados e heterogéneos, em detrimento de outras designações de abrangência mais restrita" (COUTO et al., 2010, p.48). Como a interpretação de acompanhamento abarca uma série de situações diferentes, os autores incluem a interpretação de liaison e a de comunidade (comunitária) como designações mais restritas a determinados contextos. Além da esfera de negócio ou empresarial, Couto et al. (2010) aborda outros contextos como o jurídico, o médico e o de turismo.

Em consequência dessa diversidade de contextos que se inserem na interpretação de acompanhamento, como apresentado por Couto et al. (2010), vale averiguar as peculiaridades de cada tipo de interpretação. É preciso buscar entender vários aspectos como, por exemplo, quem são os usuários do serviço de interpretação, qual o ambiente e em que situação ocorre o serviço, qual modo de interpretação mais adequado para as demandas desse tipo de interpretação e as relações de poder estabelecidas entre os participantes do ato interpretativo, dentre outros aspectos.

Todos esses elementos se alteram conforme a configuração própria de cada tipo de interpretação e o contexto mencionado pelos autores. Ou seja, são questões que refletem e podem impactar na atuação do intérprete, seja pelo modo de interação com os envolvidos, seja pelas características dos contextos que, consequentemente, podem 
implicar em atitudes e tomadas de decisões muito precisas.

Por exemplo, na esfera empresarial ou no campo dos negócios, o contato entre empresários, acionistas e proprietários que buscam a todo o momento efetivar negociações, contratos e serviços, envolvendo marcas e investimento de capital, pode gerar estresse, pressão, ansiedade e demandas complexas para o serviço de interpretação. Dito de outro modo, cobra-se do profissional da interpretação uma efetiva comunicação entre as partes negociantes. Por isso, no momento da contratação do serviço, é fundamental que a habilitação e a competência do profissional sejam, de fato, analisadas. Ou seja, cabe ao contratante se certificar que o intérprete contratado realmente tem formação e experiência para o exercício de tal atividade.

Todas as questões expostas até o presente momento oferecem indícios para constatar a incipiência desse tipo de interpretação, que requer maior investimento na pesquisa. A variação do uso dos termos é uma constante, tanto na atuação profissional quanto na produção acadêmica dos Estudos da Interpretação. As contribuições de Pagura (2003, p. 212) corroboram essa afirmação:

Falamos, comumente, em interpretação de conferências, interpretação comunitária, interpretação em tribunais ${ }^{8}$, interpretação na mídia, interpretação de acompanhamento ou ligação, interpretação médica, entre outras. A terminologia ainda não está consagrada em português, e é bastante comum os intérpretes se referirem a "escort interpreting" em inglês em vez de utilizarem "interpretação de acompanhamento".

Nessa mesma linha defendida por Pagura (2003) estão os estudos de Torres e Silva (2014). Os autores afirmam que a interpretação de acompanhamento (escort interpreting) ocorre no campo empresarial, isto é, para empresários da indústria que negociam em diferentes países. Das poucas literaturas encontradas que se referem a escort interpreting, as definições conceituais apresentadas retratam a vasta abrangência de situações espontâneas do acompanhamento, exemplificadas por Gonzalez et al. (1991) e, posteriormente, corroboradas por Torres e Silva (2014). Os autores elencam diferentes contextos de atuação neste tipo de interpretação, desde reuniões formais e visitas técnicas até coquetéis e confraternizações executivas.

Essas discussões são de suma importância, pois oferecem subsídios para problematizar a interpretação de Libras-Português na esfera empresarial. Seguindo nossa linha de raciocínio, na próxima seção, são apresentados alguns argumentos que permitem responder duas questões: (1) Estamos tratando de liaison interpreting ou 
escort interpreting na interpretação de Libras-Português em contextos empresariais? e (2) Algumas características desses tipos de interpretação estariam presentes na interpretação de Libras-Português? Para construir essa seção, que discute as aproximações e distanciamentos entre a interpretação de línguas orais e de sinais, referenciamo-nos em Pöchhacker (2010).

\section{Liaison interpreting ou Escort interpreting? E a interpretação Libras-Português na esfera empresarial?}

No Brasil, tanto a atuação de intérpretes de Libras-Português quanto a produção acadêmica, que trata dos serviços prestados na esfera empresarial, é bastante recente. Por outro lado, em países como Áustria, Itália, Estados Unidos e Austrália, os estudos sobre interpretação de línguas de sinais têm aumentado nos últimos anos, especialmente, naqueles que tratam sobre diferentes contextos de atuação para intérpretes. Mas, ainda assim, raramente o tema sobre a interpretação de línguas de sinais na esfera empresarial circula nas produções.

Em nosso país, as demandas de intérpretes de línguas de sinais para atuação em contextos específicos são cada vez mais numerosas. Rodrigues (2010), Santos (2016), Jesus (2017) e outros autores apontam, nos resultados das investigações, a necessidade de formação específica para intérpretes de línguas de sinais. Rodrigues (2010) apresentou reflexões relevantes a partir de um levantamento de pesquisa realizado com intérpretes das regiões Sudeste e Centro-oeste.

O autor constata a existência de diferentes contextos de atuação para intérpretes de Libras-Português e mostra como tais contextos agiram como espaços de formação para os profissionais. Ao especificar alguns contextos (familiar, midiático, empresariais entre outros), Rodrigues (2010) toma como base em sua argumentação autores como: Isham (1998), Munday (2009) e Pöchhacker (2009) que discutem acerca da atuação de intérpretes no âmbito internacional. Contudo, ao se tratar de línguas de sinais, Isham (1998) discute especificamente sobre o serviço de interpretação para esta língua. Os demais autores, quando mencionam as línguas de sinais, apenas demonstram a sua existência, pois seus estudos são focados nas línguas orais. Por outro lado, Santos (2016) apresenta e discute as demandas de formação e desafios encontrados na atuação de intérpretes de Libras-Português no contexto jurídico. A forma como os intérpretes são contratados e as reivindicações feitas por eles no âmbito jurídico e policial geraram 
dados preocupantes que exigem atenção.

Em contrapartida, Jesus (2017) problematiza o contexto da saúde e mostra detalhadamente os desafios interpretativos enfrentados nesta esfera, apresentando um panorama da situação atual na saúde, nas comunidades surdas e nas equipes de intérpretes de língua de sinais que atuam nesse meio. A seguir, Jesus (2017) argumenta a favor da formação de contextos específicos e discute algumas iniciativas promovidas por meio de cursos livres, workshops, eventos e disciplinas introdutórias para intérpretes de Libras-Português que atuam nesse espaço.

Embora a produção acadêmica tenha poucas investigações sobre a interpretação de Libras-Português em contextos específicos, a escassez dos estudos não significa que a atuação de intérpretes nesses espaços é inexistente. Por exemplo, a cidade de Blumenau, situada em Santa Catarina, é um polo industrial de grande destaque na Região Sul. O município sedia uma quantidade considerável de empresas, ligadas à indústria e ao comércio de distintos ramos, que empregam pessoas de toda a região. Os colaboradores surdos das mais diversas empresas dessa cidade geram grande demanda de interpretação no par linguístico Libras-Português, já que a maioria deles é usuária da Libras.

Partindo dessas considerações, observa-se, por meio de relatos informais, que boa parte das contratações dos funcionários surge com interesses diretamente relacionados à necessidade de seguir o que dispõe a lei, sob a pena de multa, caso haja descumprimento das disposições legais. Ao empregar pessoas surdas, usuárias da Libras, as empresas estão incumbidas de ofertar o serviço de interpretação, contemplando, assim, estes trabalhadores que têm uma particularidade linguística. Neste sentido, o serviço de interpretação Libras-Português ocorre por meio de uma exigência legal, tomando como base a Lei $n^{\circ} 8.213 / 1991$ e a Lei $n^{\circ} 13.146 / 2015$, a qual apresenta, no artigo $\mathrm{n}^{\mathbf{0}} 34$, orientações sobre a garantia de ambientes de trabalho acessíveis e inclusivos.

Esse é um dos primeiros pontos de distanciamento da interpretação de línguas orais e de sinais na área empresarial ou de negócios. Normalmente, o serviço de interpretação no âmbito empresarial para as línguas orais não é permeado por exigências legais para inserção de alguém no mercado de trabalho. Pelo contrário, os participantes envolvidos na interpretação em contexto empresarial dialogam no mesmo patamar ou status linguístico, afinal as decisões em torno dos negócios constituem um dos pontos 
fundamentais dessa relação de poder.

A interpretação de acompanhamento, no original em inglês, escort interpreting, segundo alguns dos autores já mencionados, caracteriza-se por um tipo de serviço relevante para fins de negociações, na compra e venda de produtos que movimentam a atividade da empresa como, por exemplo, no investimento em maquinários e tecnologias. Porém, vale mencionar que esse tipo de interpretação não é restrito ou exclusivo para fins de negociações econômicas ou políticas.

Alguns autores como Hsieh (2003), Russo (2004), Couto et al. (2010), Naimuschin (2012) e Torres e Silva (2014) explicam que tal tipo de interpretação pode ser adotado, também, para o auxílio nos trâmites de viagens, momentos de entretenimento, dentre outras necessidades, conforme a solicitação do cliente. Embora intérpretes de línguas de sinais e intérpretes de línguas orais tenham em comum a atuação na esfera empresarial, no Brasil, as demandas dos serviços de interpretação surgem de modo distinto e podem sugerir diferentes formas de conduzir o trabalho dos profissionais intérpretes nesses espaços.

Outro ponto de distinção na interpretação de acompanhamento nas línguas orais e línguas de sinais na esfera empresarial é o grau de aproximação ou distanciamento entre os usuários desses serviços. Geralmente, os usuários dos serviços de interpretação nas línguas orais são empresários, negociadores, chefes de Estado que desfrutam da interpretação para se relacionar com seus pares, inseridos em condições sociais semelhantes, tornando-se evidente o nível de igualdade entre os participantes da ocasião a ser interpretada. Os contextos de trabalho para intérpretes que atuam nesse meio remetem a diferentes situações: reuniões e encontros de negócios, eventos sociais e viagens internacionais são algumas delas. Mesmo que haja um distanciamento entre os usuários dos serviços de interpretação, eles desfrutam de certo prestígio em ocasiões que congregam representantes de diferentes países, empresas e outras organizações.

Nas línguas orais, é bastante evidente que a finalidade da interpretação de acompanhamento está muito próxima das questões econômicas e políticas. Em suma, quando se trata deste tipo de interpretação nas línguas orais, a literatura destaca como elementos importantes: a relação entre os participantes, os cenários em que se inserem os envolvidos do ato de interpretação, a finalidade da qual depende o serviço de interpretação e a diversificada nomenclatura adotada pelos autores para designar esta atividade na esfera empresarial. 
Esses são alguns dos pontos divergentes entre a interpretação de línguas orais e a interpretação de Libras-Português na esfera empresarial, incentivada pela legislação como forma de propiciar a inserção de Pessoas com Deficiência (PCDs) no mercado de trabalho, incluindo também as pessoas surdas. Ou seja, o serviço de interpretação se aplica entre empregador, ou seu representante, e empregado, o que torna evidente a diferença de poder estabelecida na relação entre estes participantes. Isso significa que cabe à empresa se adequar de acordo com a demanda do seu trabalhador, pois é ela que determinará a ocasião a ser interpretada. Desta forma, nem sempre as demandas apresentadas pelo trabalhador surdo poderão ter garantia de atendimento pela empresa. Em decorrência deste fator, o modo de interação entre empregador (ou representante) e empregado é marcado pela distinção hierárquica, característica bem menos acentuada na interpretação de línguas orais na esfera empresarial.

Outro ponto que merece destaque é a configuração do cenário em que ocorre a interpretação de línguas de sinais e a relação do intérprete com seus clientes. Tal conjuntura se dá, predominantemente, no local do estabelecimento empresarial, ou seja, dentro da estrutura física da empresa. Em regiões ou centros urbanos maiores, o cenário de interpretação de Libras-Português na esfera empresarial poderá ser abrangente e estender-se além da estrutura física da empresa, o que é incomum em cidades e regiões menores.

É fundamental que os intérpretes de Libras-Português tenham clareza dos contratos que irão estabelecer com as instituições empresariais, pois não somente honorários $^{9}$ devem ser considerados, mas também as condições propícias para a execução dos trabalhos. O profissional da interpretação estará exposto a diversos contextos e situações que precisam ser considerados não só do ponto de vista corporativo/empresarial, mas, também, linguístico, tradutório e cultural. Por exemplo, algumas das situações envolvendo admissões, demissões, reuniões, treinamentos, informativos e avisos em geral, visitas técnicas, dentre outras circunstâncias, podem configurar uma série de desafios para os intérpretes de Libras-Português.

Em casos de demissão por justa causa, o grau de complexidade do discurso e questões relativas aos aspectos emocionais dos envolvidos (em alguns casos, com ânimos exaltados) pode exigir do intérprete posturas e impostação vocal mais assertivas, que nem sempre são trabalhadas na formação desses profissionais. De modo geral, essas situações podem propiciar maior proximidade na relação intérprete e pessoa surda ou 
intérprete e empregador, dependendo do caso. Desta forma, grande parte das características presentes na interpretação de Libras-Português, na esfera empresarial, indica maior proximidade com as características da interpretação comunitária. Ou seja, o status e os papéis desempenhados pelos participantes (empregado/empregador) se apresentam em níveis desiguais.

Essa realidade, enfrentada no cenário brasileiro para a interpretação de LibrasPortuguês na área empresarial, é bastante divergente das circunstâncias descritas para o mesmo contexto no que concerne à interpretação de diálogo ou de acompanhamento, discutida por Couto et al. (2010), Torres e Silva (2014), Hsieh (2003), Pöchhacker (2010) e Russo (2004). Ou seja, essas formas de interpretação, nas línguas orais, estão implicadas em contextos que envolvem fins econômicos, corporativos, administrativos, políticos, diplomáticos, dentre outros.

\section{Considerações finais}

O processo de globalização tem contribuído para a expansão de diversos contextos sociais, econômicos, linguísticos e culturais, dentre outros. As empresas com mais de 100 funcionários, segundo a Lei 8.213/1991, são obrigadas a reservar uma porcentagem de suas vagas para reabilitados da Previdência Social ou Pessoas com Deficiência (PCDs). A legislação que prevê a inclusão de PCDs nas empresas também indica as adaptações necessárias para receber estes funcionários. O texto evidencia que as alterações devem partir das entidades empregadoras, observando a particularidade de seu empregado.

Até então, pouco se sabia sobre os serviços de interpretação Libras-Português, ou ainda, sobre os profissionais que atuam na esfera empresarial. A escassez de materiais ou produções acadêmicas sobre esta temática e as raras discussões sobre a relevância desse profissional nessa esfera são alguns motivos que cooperam para a invisibilidade dos serviços de interpretação nesse meio. No intuito de lançar luz a essa temática, este artigo apresenta e discute algumas nomenclaturas atribuídas ao profissional que trabalha nesse campo, assim como traz a debate implicações sobre esses conceitos e sobre a atuação de intérpretes de Libras-Português na esfera empresarial.

A fim de compreender melhor essa esfera de atuação para intérpretes, os esforços desta produção se voltaram para a pesquisa bibliográfica e o exame das 
seguintes expressões: interpretação de acompanhamento, interpretação de ligação, interpretação liaison, escort interpreting e interpretação empresarial. Pode-se verificar que essa área de interpretação apresenta uma série de variações no uso da nomenclatura, tais como: interpretação de acompanhamento, utilizada por Couto et al. (2010), Torres e Silva (2014) e Scapol (2016); liaison interpreting (interpretação comunitária), proposta por Pöchhacker (2010), Hsieh (2003) e Russo (2004), ou ainda, escort interpreting, como afirma Torres e Silva (2014). Essas discussões iniciais podem oferecer pistas para uma melhor compreensão sobre as demandas de interpretação de Libras-Português na esfera empresarial.

Por fim, constata-se a necessidade de incentivar a realização de pesquisas que tenham como objetivo averiguar, detalhadamente, esses conceitos e o modo como eles operam em cada tipo de interpretação, seja de diálogo, seja de acompanhamento. Conhecendo melhor as singularidades conceituais e as boas práticas adotadas por profissionais da interpretação nas diferentes situações que envolvem a esfera empresarial, observa-se que a correlação, cada vez mais frequente, entre os conceitos e as situações nas quais são aplicáveis, contribui para o amadurecimento e a consolidação da interpretação de diálogo e de acompanhamento em nosso país. A interpretação na esfera empresarial está em constante construção.

\begin{abstract}
In Brazil, the concepts of "liaison interpretation" and of "escort interpretation", used in sign languages, have been represented by only a few discussions in the academic productions of Interpretation Studies. This text presents and discusses some of the nomenclatures assigned to the performance of interpreters in the business area, such as the escort interpreting, in Brasil known as "interpretação de acompanhamento", or liaison interpreting, popularly disseminated in this country as "interpretação de ligação". In academic productions, this same kind of interpretation is named as community interpretation. Couto et al. (2010), Torres and Silva (2014), Hsieh (2003), Pöchhacker (2010), and Russo (2004) are some of the authors who support this study. The text is structured in the following sections: the introduction presents the main demands of this field; the next part proposes a reflection on Interpretation Studies and the business area; the third part discusses the variety of names attributed to the professional working in this field, and the implications of these concepts in the performance of PortugueseLibras' interpreters. In the final remarks, the main topics discussed in the text are listed from a more inclusive and mature perspective.
\end{abstract}

Keywords: Interpretation Studies; Escort Interpretation; Liaison Interpretation; Libras-Portuguese Interpreters; Business area. 


\section{Resumen}

En Brasil, los conceptos de "interpretación de enlace" y de "interpretación de acompañamiento", utilizados en las lenguas de señas, han sido poco investigados en la producción académica de los Estudios de Interpretación. Este texto presenta y discute algunas nomenclaturas designadas para la actuación de intérpretes en la esfera empresarial tal como en la interpretación de acompañamiento, también conocida como escort interpreting o liaison interpreting $\mathrm{y}$, popularmente, diseminada como "interpretación de enlace" o, como aparece en las producciones académicas, "interpretación comunitaria". Este trabajo está teóricamente apoyado por Couto et al. (2010), Torres y Silva (2014), Hsieh (2003), Pöchhacker (2010) y Russo (2004). La introducción de este estudio presenta las principales demandas de ese ámbito; en las secciones siguientes, este estudio discute las diversas nomenclaturas atribuidas al profesional que trabaja en este ámbito y las consecuencias de esos conceptos en la actuación de los intérpretes de Libras-Portugués. En las consideraciones finales, retoma los principales tópicos discutidos a lo largo del texto, desde una perspectiva más completa y madura.

Palabras-clave: Estudios de Interpretación. Interpretación de acompañamiento. Interpretación de enlace. Intérpretes de Lengua Brasileña de Señas-Portugués. Área Empresarial.

\section{Referências bibliográficas}

BRASIL. Lei 8.213, de 24 de julho de 1991. Dispõe sobre os planos da Previdência Social e dá outras providências. Brasília, 1991. Disponível em: <http://www.planalto.gov.br/ccivil_03/leis/L8213cons.htm>. Acesso em: 03 abr. 2016.

Lei no 13.146, de 6 de julho de 2015. Dispõe sobre a Lei Brasileira de Inclusão da Pessoa com Deficiência. Disponível em: <http://www.planalto.gov.br/ccivil_03/_Ato2015-2018/2015/Lei/L13146.htm>. Acesso em: 10 out. 2017.

CAVALLO, Patrizia; REUILLARD, Patrícia Chittoni Ramos. Estudos da Interpretação: tendências atuais da pesquisa brasileira. Letras \& Letras, v. 32, n. 1, p. 353-368, 2016. Disponível em: <http://www.seer.ufu.br/index.php/letraseletras/article/view/33199>. Acesso em: 13 set. 2017.

COUTO, Alberto et al. Traduzir palavras, aproximar culturas: o ensino da Interpretação de Acompanhamento no ISCAP. Polissema: Revista de Letras do ISCAP, v. 10, n. 10, p. 43-64, 2010. Disponível em: <http://recipp.ipp.pt/handle/10400.22/2922>. Acesso em: 29 jul. 2015.

GINEZI, LucianaLatarini. Cafés do Brasil: estudo de variantes em português e inglês na língua falada. 2007. 270 f. Dissertação (Mestrado em 'Estudos Linguísticos e Literários em Inglês') - Faculdade de Filosofia, Letras e Ciências Humanas, Universidade de São Paulo, São Paulo, 2007. Disponível em: http://www. teses. usp. br/teses/disponiveis/8/8147/tde-03042008-134508/ Acesso em: 18 jan. 2016. 
Gonzalez, Roseann Duenas et al. Fundamentals of Court Interpretation: Theory, Policy, and Practice. Durham, NC: Carolina Academic Press, 1991.

HSIEH, Elaine. The importance of liaison interpreting in the theoretical development of translation studies.In:Seventh Symposium on the Teaching of Translation and Interpretation,Taipei, Taiwan. 2003. Disponível em:

<http://faculty-staff.ou.edu/H/Elaine.K.Hsieh-1/download/Hsieh2003-2.pdf〉.

Acessoem: 18 jan. 2016.

ISHAM, William P. Signed language interpreting. In: BAKER, M. (org.) Routledge encyclopedia of translation studies. 1 st edition. London and New York: Routledge, 1998. p. 231-235.

JESUS, Ringo B. "Ei aquele é o intérprete de Libras?" Atuação de intérpretes de Libras no contexto de saúde. 2017. 194 f. Dissertação (Mestrado em 'Estudos da Tradução') - Centro de Comunicação e Expressão, Universidade Federal de Santa Catarina, Florianópolis. 2017. Acessoem 18 set. 2017.

MUNDAY, Jeremy.The Routledge Companion to Translation Studies.[Abingdon]: Routledge, 2009.

NAIMUSHIN, Boris. Tightrope-walking on the Moral High Wire: Ethical DecisionMaking in Conference and Escort Interpreting. Frankfurt: Peter Lang, 2012.

Disponível em:

<http://eprints.nbu.bg/1682/1/Naimushin_Ethical_Decision_Making_Translata_2011.pd f>. Acesso em: 18 jan. 2016.

PAGURA, Reynaldo. A interpretação de conferências: interfaces com a tradução escrita e implicações para a formação de intérpretes e tradutores. DELTA: Documentação de Estudos em Linguística Teórica e Aplicada. v.19 e n. esp, p.209-236, 2003.

Disponível em:

http://www.scielo.br/scielo.php?pid=S0102-

44502003000300013\&script=sci_abstract\&tlng=pt Acesso em: 20 jun. 2017.

PEREIRA, Maria Cristina Pires. Interpretação interlíngue: as especificidades da interpretação de língua de sinais. Cadernos de Tradução, Florianópolis, v. 1, n. 21, p. 135-156, 2008. Disponível em:

https://periodicos.ufsc.br/index.php/traducao/article/view/2175-7968.2008v1n21p135

Acesso em: 15 fev. 2016.

Produções Acadêmicas sobre Interpretação de Língua de Sinais: dissertações e teses como vestígios históricos. Cadernos de Tradução, Florianópolis, v. 2, n. 26, p. 99-117, 2010. Disponível em:

https://periodicos.ufsc.br/index.php/traducao/article/view/2175-7968.2010v2n26p99

Acesso em: 20 abr. 2016. 
Reflexões sobre a tipologia da interpretação de línguas de sinais. Cadernos de Tradução, Florianópolis, v. 35, n. 2, p. 46-77, 2015. Disponível em: https://periodicos.ufsc.br/index.php/traducao/article/view/2175-7968.2015v35nesp2p46 Acesso em: 15 fev. 2016.

PÖCHHACKER, Franz. Introducing Interpreting Studies, London and New York: Routlegde, 2004.

Issues in Interpreting Studies. In: MUNDAY, Jeremy. The Routledge Companion to Translation Studies.London: Routledge. 2009, p.128-140.

; QUEIROZ, Mylene. Conexões Fundamentais: Afinidade e Convergência nos Estudos da Interpretação. ScientiaTraductionis, Florianópolis, n. 7, p. 61-75, 2010. Disponível em: https://periodicos.ufsc.br/index.php/scientia/article/view/13946 Acesso em: 10 abr. 2016.

QUEIROZ, Mylene. Interpretação Médica no Brasil. 2011. 137 f. Dissertação (Mestrado em 'Estudos da Tradução') - Centro de Comunicação e Expressão, Universidade Federal de Santa Catarina, Florianópolis. 2011. Disponível em: https://repositorio.ufsc.br/handle/123456789/95825?show=full Acesso em: $10 \mathrm{fev}$. 2016.

RODRIGUES, Carlos Henrique. Da interpretação comunitária à interpretação de conferência: desafios para formação de intérpretes de língua de sinais. In: Congresso Brasileiro de Pesquisa em Tradução e Interpretação de Língua de Sinais Brasileira, II, 2010, Florianópolis. Anais, Florianópolis: UFSC, 2010. p.01-07. Disponível em: http://www.congressotils.com.br/anais/anais2010/Carlos\%20Henrique\%20Rodrigues.pdf Acesso em: 10 jan. 2016.

; BEER, Hanna. Os estudos da tradução e da interpretação de línguas de sinais: novo campo disciplinar emergente? Cadernos de Tradução, Florianópolis, v. 35, n. 2, p. 17- 45, 2015. Disponível em: https://periodicos.ufsc.br/index.php/traducao/article/view/2175-7968.2015v35nesp2p17 Acesso em: 27 set. 2017.

RUSSO, M. Community Interpreter, Liaison Interpreter, ad hoc Interpreter, Intercultural Mediator... What kind of curriculum for such a multifaceted profession. In: Professionalization of interpreting in the community, 4, 2004, Estocolmo. Artigo, Estocolmo: International Conference Critical Link, 2004. p. 1-9. Disponível em: http://static1.squarespace.com/static/52d566cbe4b0002632d34367/t/5347f79be4b0b891 fcd56cad/1397225371847/CL4_Russo.pdf . Acesso em: 15 fev. 2016.

SANTOS, Silvana Aguiar dos. Tradução/interpretação de língua de sinais no Brasil: uma análise das teses e dissertações de 1990 a 2010. 2013. 313 f. Tese (Doutorado em 'Estudos da Tradução') - Centro de Comunicação e Expressão, Universidade Federal de Santa Catarina , Florianópolis, 2013. Disponível em: http://www.bu.ufsc.br/teses/PGET0178-T.pdf . Acesso em: $1^{\circ}$ jun. 2016.

Questões emergentes sobre a interpretação de libras-português na esfera jurídica. 
Belas Infiéis, Brasília, v. 5, n. 1, p. 117-129, 2016. Disponível em: http://periodicos.unb.br/index.php/belasinfieis/article/view/19511. Acesso em: 1 jun. 2017.

SCAPOL, Evelise C. Interpretação de acompanhamento em indústrias - um relato sobre as particularidades da função. In: Coleção Tópicos e Contextos em Interpretação, Londrina, v. 1, p. 01-22, 2016. Disponível em:

<http://www.interpret2b.com/publicacoes>. Acesso em: 10 jun. 2016.

TORRES, Milton L.; SILVA, Josiane. Comportamentos e atitudes essenciais na interpretação de acompanhamento: A perspectiva dos clientes. Tradterm, São Paulo, v. 23, p. 35-57, 2014. Disponível em:

<www.revistas.usp.br/tradterm/article/download/85566/88355>.Acesso em: 4 out. 2015.

WADENSJÖ, Cecília. The double role of a dialogue interpreter. In: PÖCHHACKER, Franz and SHLESINGER, Mirian (eds). The Interpreting Studies Reader. London / New York: Routledge. 2002. p. 355-370.

\section{Notas}

${ }^{1}$ A notícia foi veiculada na seção de Classificados do Jornal de Santa Catarina, Blumenal (2014). As notícias publicadas por esse jornal abrangem não somente a cidade de Blumenau, mas também, aqueles municípios que congregam a microrregião e mesorregião do Vale do Itajaí de Santa Catarina. Acesso em: http://jornaldesantacatarina.clicrbs.com.br/sc/

${ }^{2}$ Empregou-se como método, neste artigo, a abordagem qualitativa, por meio de uma pesquisa documental, que investiga principalmente a variação dos conceitos de: interpretação de acompanhamento, interpretação de ligação, interpretação liaison, escort interpreting e interpretação empresarial dentro dos Estudos da Interpretação. A coleta de dados ocorreu no segundo semestre de 2015 e registrou diferentes nomenclaturas nas referências bibliográficas.

${ }^{3}$ Duas pesquisas inspiraram a circulação dos estudos e das contribuições de Pöchhacker (2004), a saber, Rodrigues (2010) e Queiroz (2011). Recentemente, Jesus (2017) problematizou as considerações realizadas por Pöchhacker (2004) como aporte teórico para a interpretação de Libras-Português em contextos de saúde.

${ }^{4}$ Conforme Pöchhacker (2010), até então o que se trabalhava nos estudos da interpretação era a abordagem do discurso monológico, encontrado da interpretação de conferência, o discurso onde uma pessoa se manifesta para várias outras que a assistem (de um para muitos). Com o surgimento da interpretação comunitária, a abordagem recaiu sobre a relação entre os participantes do ato interpretativo, e foi designada "relação triádica", onde o discurso dialógico entre duas pessoas passa por um terceiro, o intérprete. Pöchhacker (2010, p. 67) refere-se à: "perspectiva da interpretação de Cecília Wadensjö como sendo um discurso administrado numa relação triádica, onde o foco recai mais na interatividade do que na produção monológica de um texto", e que essa forma de discurso "deu forma a um novo paradigma".

${ }^{5}$ Pöchhcker usa a noção de paradigma de Tomas Kuhn: suposições básicas, modelos, valores e métodos compartilhados por membros de uma dada comunidade científica (PÖCHHACKER, 2004, 2010).

${ }^{6}$ No texto há a variação dos termos tanto em inglês quanto em português, isto é, escort interpreting e interpretação de acompanhamento.

7 “[...] "liaison interpreter" (as defined by Gentile et al. 1996) or to an "intérprete de enlace" (as defined by ColladosAís and Fernández Sánchez 2001), who not necessarily belongs to the same ethnic group as 
the client and operates also in business settings.”(RUSSO, 2004, p.3)

${ }^{8}$ A interpretação realizada em tribunais durante julgamento no Brasil é, por força da legislação, uma atribuição do tradutor público (juramentado). Tal fato corrobora com a confusão existente entre tradutor e intérprete.

${ }^{9}$ Sugere-se que intérpretes estejam atentos aos honorários indicados pela Federação Brasileira das Associações dos Profissionais Tradutores e Intérpretes e Guia-Intérpretes de Língua de Sinais (Febrapils). Mais informações em: http://www.febrapils.com.br/2016/01/tabela-de-honorarios.html. Acesso em: 1 Nov. 2017. 